\title{
Title: An ultrasound absorbing inflorescence zone enhances echo- acoustic contrast of bat-pollinated cactus flowers
}

Authors: Ralph Simon ${ }^{1}$, Felix Matt ${ }^{2,3}$, Vinicio Santillan, ${ }^{4}$ Marco Tschapka5,6, Merlin Tuttle ${ }^{7}$ Wouter Halfwerk ${ }^{1}$

\author{
${ }^{1}$ Department of Ecological Science, Vrije Universiteit, Amsterdam, The Netherlands \\ 2Estación Científica San Francisco, Loja, Ecuador \\ ${ }^{3}$ Faculty of Geography, Lab for Climatology and Remote Sensing, Philipps-University of Marburg, Germany \\ ${ }^{4}$ Universidad Católica de Cuenca, Cuenca, Ecuador \\ ${ }^{5}$ Institute of Evolutionary Ecology and Conservation Genomics, University of Ulm, Germany \\ ${ }^{6}$ Smithsonian Tropical Research Institute, Ancon, Balboa, Panama \\ ${ }^{7}$ Merlin Tuttle's Bat Conservation, Austin, Texas
}

Running title: ultrasound absorbing inflorescence zones in a bat-pollinated cactus

Key words: floral acoustics, echolocation, bat-pollination, chiropterophily, Cactaceae, cephalium, ultrasound absorption

\section{Abstract}

1 Flowering plants have evolved an extraordinary variety of signaling traits to attract and guide their pollinators. Most flowers rely on visual and chemical signals, but some batpollinated plants have evolved reflective surfaces to acoustically guide echolocating bats. All known echo-acoustic flower signals rely on the same basic acoustic principles of increased sonar reflectivity. Here we reveal a novel mechanism through which plants acoustically communicate with bats, a principle that relies on increased absorption of the area surrounding the target flower, thereby enhancing echo-acoustic contrast. In a batpollinated columnar cactus (Espostoa frutescens) from the Ecuadorian Andes we found a hairy inflorescence zone, a so called lateral cephalium. Flowers of this cactus solely emerge out of this hairy zone. We measured the ultrasound echoes of the hairy zones, the flowers and unspecialized column surfaces with a biomimetic sonar head and recorded echolocation calls of approaching bats. We found that the hairy inflorescence zones act as strong ultrasound absorber, attenuating the sound by $-14 \mathrm{~dB}$ compared to other parts of the column. The absorption was highest around the echolocation call frequencies of approaching bats. Our results indicate that, instead of making flowers more reflective, plants can also evolve specific structures to attenuate the background echo, thereby enhancing the acoustic contrast with the target. Similar sound absorbing mechanisms may be found in other species that interact with bats across a wide range of ecological contexts. 


\section{Introduction}

21 Flowering plants rely on a wide variety of communication strategies to attract their pollinators. Conspicuous visual flower signals are in particular useful to guide receivers, as they are easy to locate and the use of colours makes flowers stand out against the vegetation background [1,2]. Nocturnally flowering bat-pollinated plants however are limited in the use of visual signals to attract their pollinators. Several plants have therefore independently evolved echo-reflective structures to acoustically guide these nocturnal pollinators [3-6]. Echo-acoustic signalling plants all use concave shapes with either triple mirror, bell- or dish-like structures. These concave shaped structures share the same basic acoustic principle of focusing returning echoes to an approaching bat, thereby increasing the range over which they can be detected. Some flower signals use additional spectral-temporal signatures increasing conspicuousness [4]. Reflective structures also evolved in bat-plant-interactions even outside a pollination context. The carnivorous pitcher plant Nepenthes hemsleyana, for example, has a highly reflective prolonged pitcher backwall to advertise their pitcher-leaves as roosts [6]. Bats roosting inside the pitcher provide additional nitrogen intake through their droppings[7].

Here we assess an evolutionary novel adaptation that enhances acoustic communication between plants and pollinating bats. Interestingly, some cacti species exhibit at a certain age inflorescence zones that are particularly hairy, the so-called cephalium. There are several different morphologies of cacti described as cephalia, and we refer here to what is described as a lateral cephalium by Mauseth (2006) [8]. Several functions of these cephalia zones, have been proposed. The hairy structure may shield buds from UV radiation at high altitudes, or protect against nectar robbers and herbviores [8-10]. Here we test a hypothesis by von Helversen et al. (2003) [5], which states that such hairy zones may have been co-opted to serve in bat-pollinated cacti as sound-absorbing structures that support detection and localization of sound-reflecting flowers by pollinating bats.

Using a bat-mimetic sonar-head we carried out ensonification experiments with different parts of the cactus Espostoa frutescens [5] from the Andes. Specifically, we ensonified the cactus' column, flowers as well as the hairy cephalium zone. Additionally, we recorded the echolocation calls of its main pollinator, the nectar-feeding bat Anoura geoffroyi 50 (Phyllostomidae) and assessed whether the cephalium was especially absorbent in the ultrasonic frequency range of the calls. 


\section{Material and Methods}

53

We studied Espostoa frutescens and its pollinator, Anoura geoffroyi. The study was carried out in a dry valley of the Ecuadorian Andes, close to the city Oña in the province of Azuay. As it was not possible to conduct the echo measurements in the field - the cacti are growing in rocky and steep habitat - we cut the columns and conducted the measurements indoors at a nearby farm. All experiments where approved by the local authorities (Ministeria del Ambiente, Cuenca, Ecuador, autorizacion para investigación científica N. 035-DPA-MA-2012). A specimen is deposited at Herbario Azuay (Cuenca, Ecuador) with the number HA 7814.

To measure the reflectance of the different parts of the cacti we mounted the columns on tripods and used a custom-built biomimetic sonar head to ensonify them. The sonar head consisted of a 1/4" condenser microphone (40BF; preamplifier 26AB; power module 12AA; G.R.A.S. Sound \& Vibration, Holte, Denmark) and a custom-made EMFi (Electro Mechanical Film) loudspeaker (sound pressure levels at $1 \mathrm{~m}$ distance: $92 \mathrm{~dB} \pm 8 \mathrm{~dB}$, frequency range: 30-160 kHz; Department of Sensor Technology, University of ErlangenNuremberg, Erlangen, Germany). The speaker and the microphone were embedded in an aluminium body and placed next to each other as they would be located on the head of a bat. We ensonified cacti from a distance of $15 \mathrm{~cm}$ with a continuously replayed MLS Signal (Maximum Length Sequence) of 16383 samples length. We recorded the reflected sound and obtained the impulse responses (IR) by deconvolution of the reflected echo and the original MLS [5]. The spectral target strength was obtained by windowing the IRs (1024 samples) and calculating the power spectral density (PSD). To obtain spectral target strength (TS), independent of the frequency response of the loudspeaker, we calculated the difference between PSD from the reflector and the PSD of an acrylic glass plate oriented perpendicular to the direction of sound propagation at exactly the same position as the column/flower (For more information on the setup see also [4, 5, 11]).

Using our ensonification setup we measured the acoustic properties of six freshly cut columns of $E$. frutescens, focusing on the hairy cephalium zone and the unspecialized parts (backside) of the column. For both measurements we scanned the columns by moving the sonarhead upwards along its vertical axis and made 10 measurements at different heights of the column. We also measured the reflectance of six isolated flowers, which were 
83

mounted on a stepping motor. We rotated the flower in $3^{\circ}$ steps and measured 20 echoes around the opening $\left(0^{\circ}\right)$ of the flowers from $-30^{\circ}$ to $30^{\circ}$.

To understand how the echo of a flower would be received if it would grow on an unspecialized part of the column we manipulated one column. We first scanned the hairy cephalium with an open flower by moving the sonar head upwards along the vertical axis of the column over an area of $30 \mathrm{~cm}$. The flower was located central on this area and we measured in $1 \mathrm{~cm}$ steps. After the measurements we cut out the flower from the cephalium and fixed it on the hairless backside of the column (Fig. 2B). For this experimentally manipulated column we made the same detailed vertical scan $(30 \mathrm{~cm}, 1$ cm steps).

We also recorded echolocation calls of two male Geoffroy's tailless bats (Anoura geoffroyi) approaching an Espostoa column with an open flower. The microphone (1/4" condenser microphone 40BF; preamplifier 26AB; power module 12AA; G.R.A.S. Sound \& Vibration, Holte, Denmark) was placed next to the flower and we recorded with a sampling rate of $500 \mathrm{ks} / \mathrm{s}$. We obtained 45 manually triggered recordings, each with a length of $2 \mathrm{~s}$, during the approaches of the bats. To ensure a good signal-to-noise-ratio for the call analysis we selected 21 approach sequences where at least two calls had an amplitude of more than $6 \%$ full scale. We analysed the calls using the program Avisoft-SASLab Pro (Avisoft Bioacoustics, Glienicke, Germany).

We tested for significant effects of plant structure on echo-acoustic target strength using the lmer package in R (version 3.5.3). We constructed linear mixed models and checked model assumptions by visual inspection of the residuals. Target strength was averaged over the 10 measurements per plant individual and structure and modelled as dependent variable. Plant structure (column, flower or cephalium) was added as fixed factor and plant individual as a random intercept term. For the different frequency ranges we modelled the interaction between plant part and frequency band. We tested for significance of main effect of plant structure on target strength and for significance of the interaction between structure and frequency band by comparing models with and without terms using likelihood ratio tests. 

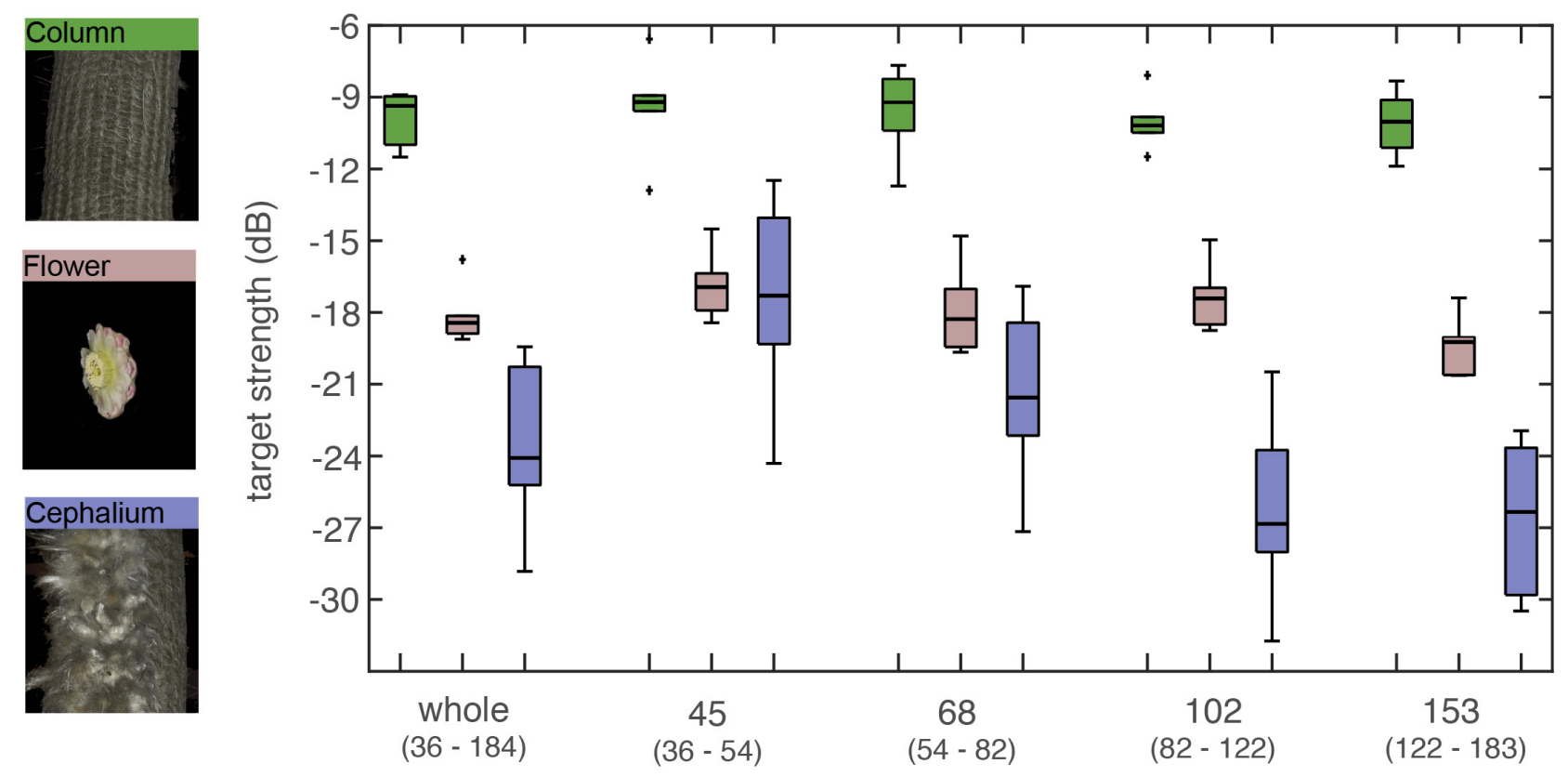

frequency band $(\mathrm{kHz})$

Figure 1. Spectral target strength (TS) of different morphological structures of Espostoa frutescens for different frequency bands. The spectral target strength was obtained from ensonification measurements at a distance of $15 \mathrm{~cm}$. We measured unspecialized parts of the cactus column (green boxplots; $n=6$ columns, 10 measurements per column), isolated flowers (rose boxplots; $n=6$ columns, 20 measurements per flower from different angles) and the hairy cephalium zone (purple boxplots; $\mathrm{n}=6$ columns, 10 measurements per column).

\section{Results}

113 We found a significant effect of plant structure on overall target strength (LMM, $\mathrm{n}=18$

114 plant structures, $\mathrm{n}=180$ measurements, d.f. $=2, \mathrm{X} 2=39.31, \mathrm{P}<0.001$ ). Furthermore,

115 target strength depended on the interaction between frequency range and plant structure

116 (LMM, d.f. $=8, \mathrm{X} 2=37.51, \mathrm{P}<0.001)$. Overall, the plain column surface of $E$. frutescens

117 reflected the strongest echoes. We measured a high target strength (average TS -9.8 dB)

118 for these unspecialized surfaces of the cactus across a wide range of frequencies (Fig. 1).

119 The overall average TS of the flower was much lower compared to the column $(-18.1 \mathrm{~dB})$

120 but also remained similar across all measured frequency bands (Fig 1). The hairy

121 cephalium zone on the other hand showed differences in TS for the different frequency

122 bands (Fig 1). For the lower frequency band (45 kHz) the TS was about the same level as

123 the flower $(-17.5 \mathrm{~dB})$ but for higher frequency bands it was much lower, down to $-26.3 \mathrm{~dB}$

124 for the $102 \mathrm{kHz}$ frequency band. Overall, the cephalium zone had an average target 


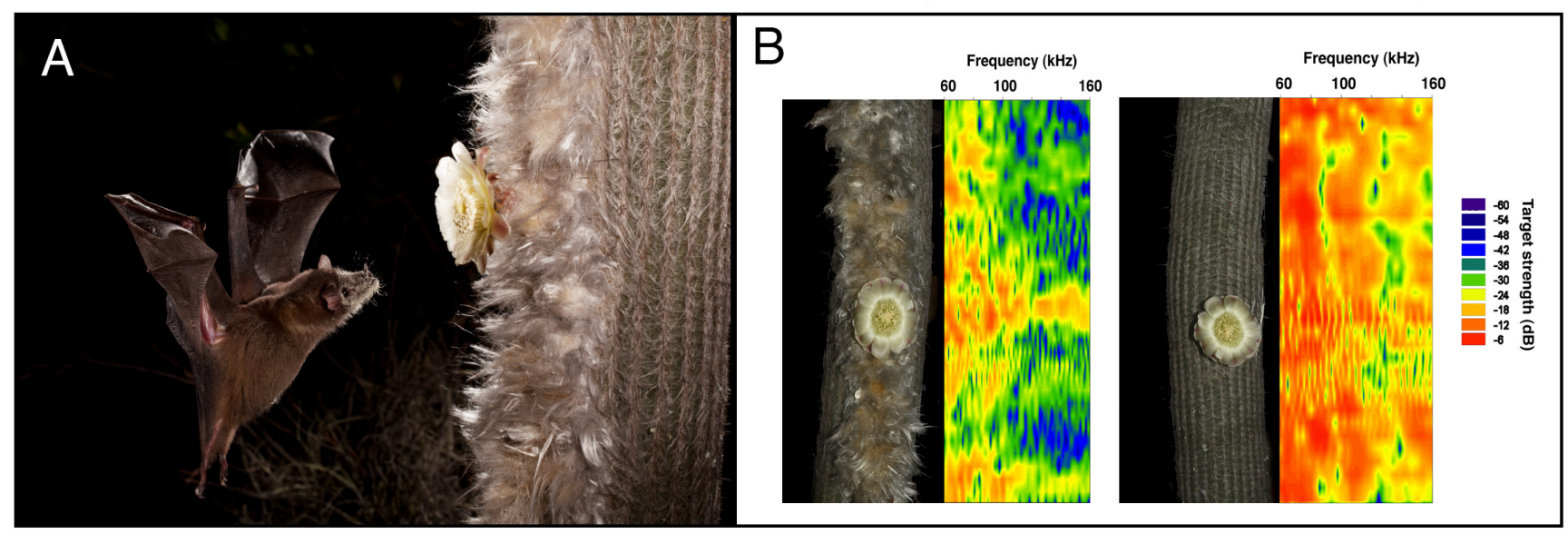

Figure 2. Nectar-feeding bat approaching a flower and echo fingerprints of different cactus surfaces with flowers. (A) Image of a Geoffroy's tailless bat (Anoura geoffroyi) approaching a flower of Espostoa frutescens, which is in embedded in the hairy cephalium zone (photo credit: Merlin Tuttle's Bat Conservation). (B) Echo fingerprints of acoustic scans along the cactus column. The left column is a natural column with cephalium and flower, for the right measurement we experimentally manipulated the column. The flower was cut out of the hairy zone and fixed on an unspecialized part of the column. The intensity (spectral target strength in $\mathrm{dB}$ ) of the echo is given in colour gradation (red indicates high intensities, blue low intensities).

strength of $-23.7 \mathrm{~dB}$, which is around $14 \mathrm{~dB}$ lower than the unspecialized parts of the

126 column.

127 A qualitative analysis of the echo-acoustic fingerprint of specialized versus unspecialized

128 parts of the column revealed more detailed insight into the effect of the background on

129 detectability of flower targets (Fig 2B). The unspecialized column reflects high TS echoes

130 for almost the entire bandwidth, which are only sometimes interrupted by some

131 frequency notches. The specialized cephalium side of the column reflects much less sound

132 energy, especially for frequencies above $90 \mathrm{kHz}$. When scanning the column at the

133 position of the flower, the unmanipulated flower stands out from the less-reflecting

134 background, in particular at frequencies above $90 \mathrm{kHz}$. When we placed a flower on the

135 unspecialized part of the column the flower echoes almost completely disappear within

136 the loud background echoes, although there might be some additional interference

137 patterns affecting the TS.

138 In total we analysed 279 echolocation calls of two individuals of A. geoffroyi, see Fig. 3 for

139 an example of an echolocation call sequence during an approach to an E. frutescens 


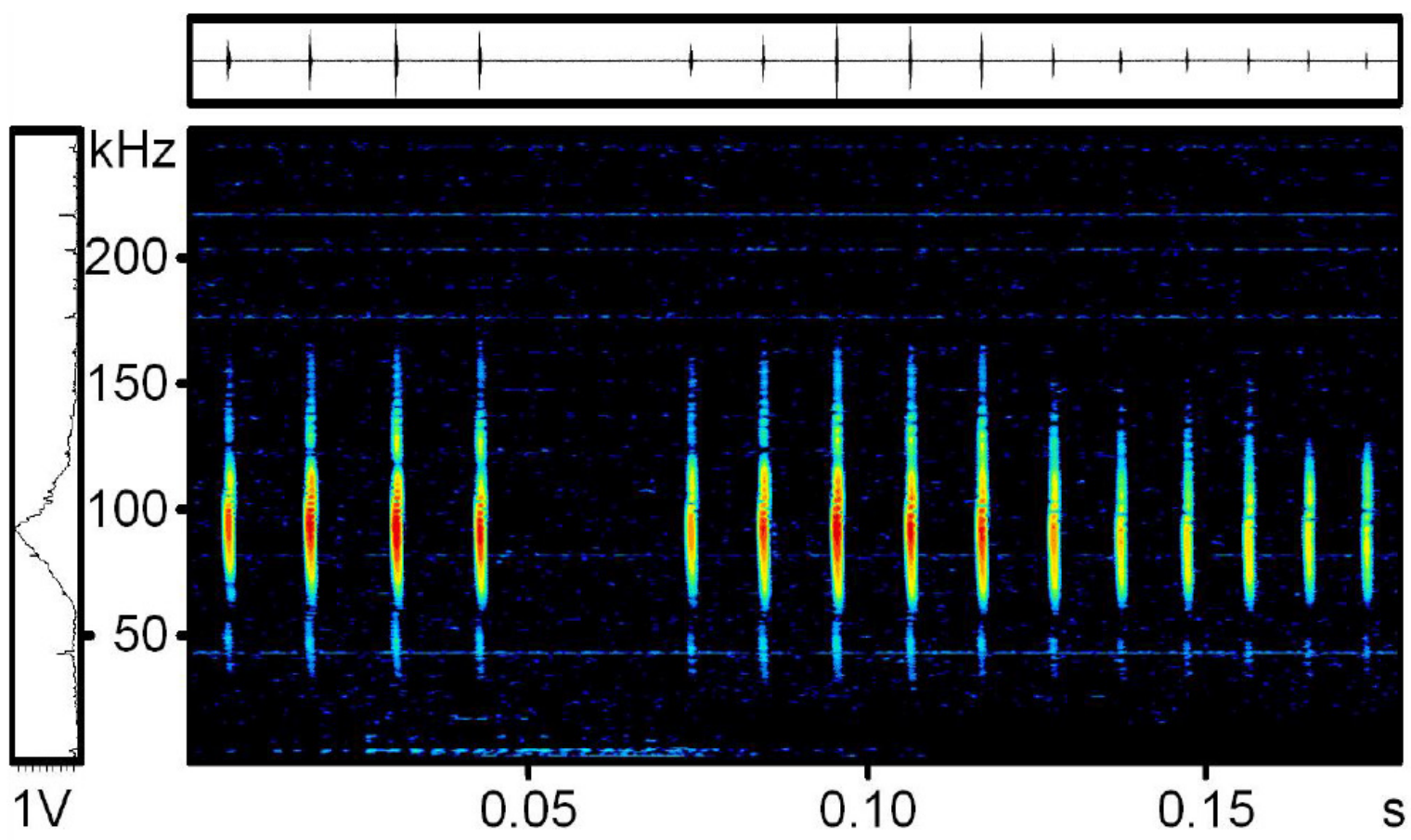

Figure 3. Typical series of calls of a Geoffroy's tailless bat (Anoura geoffroyi) while approaching an Espostoa frutescens flower. The microphone (1/4" G.R.A.S. free field microphone) was place next to the flower.

140 flower. The calls where short, having a duration of only $0.47 \mathrm{~ms} \pm 0.18 \mathrm{~ms}$ (mean \pm SD)

141 and they were step frequency modulated starting at $132.7 \mathrm{kHz} \pm 8.1 \mathrm{kHz}$ and ending at $14259.8 \mathrm{kHz} \pm 10.0 \mathrm{kHz}$. The peak frequency of the calls was at $92.5 \mathrm{kHz} \pm 4.4 \mathrm{kHz}$, which falls 143 into the frequency band where sound absorption of the cephalium was highest.

\section{Discussion}

145 Our ensonification experiments revealed distinct and frequency-dependent differences in 146 echo-acoustic reflectance of different cacti parts. We found that the plain column of 147 Espostoa acts as a strong reflecting surface as it is cylindric, providing reflective surfaces 148 from all directions, and also because the surface has ridges, which may additionally act as 149 small retroreflectors. The flowers of Espostoa reflect much less energy compared to the 150 column, mainly due to the facts that the reflecting surface is smaller and that flowers have 151 a lot of anthers, which scatter the sound energy. The specialized cephalium surrounding 152 the flowers reflected the least energy, in particular in the echolocation call frequency 153 range of the plant's main pollinator, A. geoffroyi. These results strongly suggest that the 154 cephalium of Espostoa functions as a sound-absorbing structure and thus enhances the 
echo-acoustic contrast between the flower and the vegetative part of the plant for an approaching bat. While scanning cacti columns for flowers along the cephalium the bats will receive faint echoes unless their call hits a flower, which increases the echo response by around $10 \mathrm{~dB}$. In contrast, flowers growing on the unspecialized parts of the column would be much more difficult to recognize in front of the highly reflective background. Bats might be able to pick up on the interference patterns caused by the flowers, however, this would require much more processing than a salient flower echo in front of an absorbing surface.

Such a simple yet efficient mechanism of dampening the background of the flowers thus may help the bats to save on foraging time - nectar feeding bats have to visit or revisit several hundred flowers each night to cover their nightly energy expenditure - and thus increase foraging efficiency [12]. The plant on the other hand will benefit from a higher cross pollination rate - bats are very efficient pollinators that carry a lot of pollen in their fur (see Fig 2A) and have a huge home range so they can pollinate plants growing far apart [13].

The absorption of the cephalium is most efficient for the $102 \mathrm{kHz}$ frequency band $(82 \mathrm{kHz}$ - $122 \mathrm{kHz}$ ), which translates to a wavelength of around $3.4 \mathrm{~mm}(4.2 \mathrm{~mm}-2.8 \mathrm{~mm})$. The microstructure of the cephalium apparently favours absorption of sound around this wavelength, while larger wavelengths (e.g., $7.6 \mathrm{~mm}$ for the $45 \mathrm{kHz}$ band) are around 10 $\mathrm{dB}$ less attenuated. The hairs are much smaller in diameter than the wavelengths of sound they absorb best and therefore probably do not scatter the incoming sound waves. An alternative explanation could be that the hairs create a layer of air with different temperature that reflects the sounds in a frequency-dependent manner.

As other species of Espostoa show the same hairy cephalium zone this floral acoustic adaptation might not only be limited to this species and even other genera have similar hairy cephalium zones e.g. Microanthocereus [8]. Interestingly, bird pollinated species of the genus Microanthocereus have also cephalium zones, however the fur is much less dense. We argue that cephalium-like structures originally evolved for protection of floral structures, but was co-opted at some point in time to serve an additional or new functional role in pollinator attraction. Once co-opted, the cephalium of bat-pollinated flowers got optimized for this new function through selection by the echolocating bat pollinators. 
187 Our study reveals that bat-pollinated flowers can also rely on absorption in addition to

188 reflectance as an acoustic adaptation towards their pollinators. Echoacoustic absorption

189 likely plays a much larger role across a wide range of ecological contexts than so far has

190 been appreciated. Sound absorbent structures have already been described for moth

191 scales [14] as well as for thoracic moth fur [15]. Whether absorption has adapted in the

192 context of predator-prey arms races remains however to be tested, ideally in a 193 comparative phylogenetic framework.

\section{Acknowledgements}

195 We are very grateful to Otto von Helversen who initiated this study before his all to early 196 death. We greatly acknowledge the help from Nery Fabian Chamorro Rodas during 197 collection and the measurements of the cacti and the help from all people from Susudel 198 Granja Organica. We thank the Herbario Azuay (Patent: FLR.S-004-2019) for the 199 identification and assistance with the E. frutescens specimen.

\section{References}

[1] Spaethe, J., Tautz, J. \& Chittka, L. 2001 Visual constraints in foraging bumblebees: flower size and color affect search time and flight behavior. Proc. Natl. Acad. Sci. U.S.A. 98, 3898-3903.

[2] Forrest, J. \& Thomson, J.D. 2009 Background complexity affects colour preference in bumblebees. Naturwissenschaften 96, 921-925.

[3] von Helversen, D. \& von Helversen, 0. 1999 Acoustic guide in bat-pollinated flower. Nature 398, 759-760.

[4] Simon, R., Holderied, M.W., Koch, C.U. \& von Helversen, 0. 2011 Floral acoustics: conspicuous echoes of a dish-shaped leaf attract bat pollinators. Science 333, 631-633.

[5] von Helversen, D., Holderied, M.W. \& von Helversen, 0. 2003 Echoes of bat-pollinated bell-shaped flowers: conspicuous for nectar-feeding bats? J. Exp. Biol. 206, 1025-1034.

[6] Schöner, Michael G., Schöner, Caroline R., Simon, R., Grafe, T.U., Puechmaille, Sébastien J., Ji, Liaw L. \& Kerth, G. 2015 Bats Are Acoustically Attracted to Mutualistic Carnivorous Plants. Current Biology 25, 1911-1916. (doi:10.1016/j.cub.2015.05.054). [7] Grafe, T.U., Schöner, C.R., Kerth, G., Junaidi, A. \& Schöner, M.G. 2011 A novel resourceservice mutualism between bats and pitcher plants. Biology Letters 7, 436-439.

[8] Mauseth, J. 2006 Structure-function relationships in highly modified shoots of Cactaceae. Annals of Botany 98, 901-926.

[9] Buxbaum, F. 1961 Die Entwicklungslinien der Tribus Pachycereae F. Buxb.

(Cactaceae- Cereoideae). Botanische Studien 12.

[10] Martorell, C., Vega, E. \& Ezcurra, E. 2006 Morphological consequences of the tradeoff between growth and reproduction in a columnar cactus (Lophocereus schottii). Plant Ecology 183, 125-131.

[11] Simon, R., Holderied, M.W. \& von Helversen, 0. 2006 Size discrimination of hollow hemispheres by echolocation in a nectar feeding bat. J. Exp. Biol. 209, 3599-3609. 
bioRxiv preprint doi: https://doi.org/10.1101/2019.12.28.890046; this version posted December 28, 2019. The copyright holder for this preprint (which was not certified by peer review) is the author/funder, who has granted bioRxiv a license to display the preprint in perpetuity. It is made available under aCC-BY-NC-ND 4.0 International license.

[12] Winter, Y. \& von Helversen, 0. 2005 Bats as pollinators: foraging energetics and floral adaptations. In Cognitive Ecology of Pollination: Animal Behaviour and Floral Evolution (eds. L. Chittka \& J. Thomson), pp. 148-170. Cambridge, Cambridge University Press.

[13] Von Helversen, O. \& Winter, Y. 2003 Glossophagine bats and their flowers: costs and benefits for plants and pollinators. In Bat ecology (eds. T.H. Kunz \& M.B. Fenton), pp. 346-397. Chicago, Illinois, The University of Chicago Press.

[14] Shen, Z., Neil, T.R., Robert, D., Drinkwater, B.W. \& Holderied, M.W. 2018 Biomechanics of a moth scale at ultrasonic frequencies. Proceedings of the National Academy of Sciences 115, 12200-12205.

[15] Neil, T.R., Shen, Z., Drinkwater, B.W., Robert, D. \& Holderied, M.W. 2018 Stealthy moths avoid bats with acoustic camouflage. The Journal of the Acoustical Society of America 144, 1742-1742.

\section{Supplementary Figure}
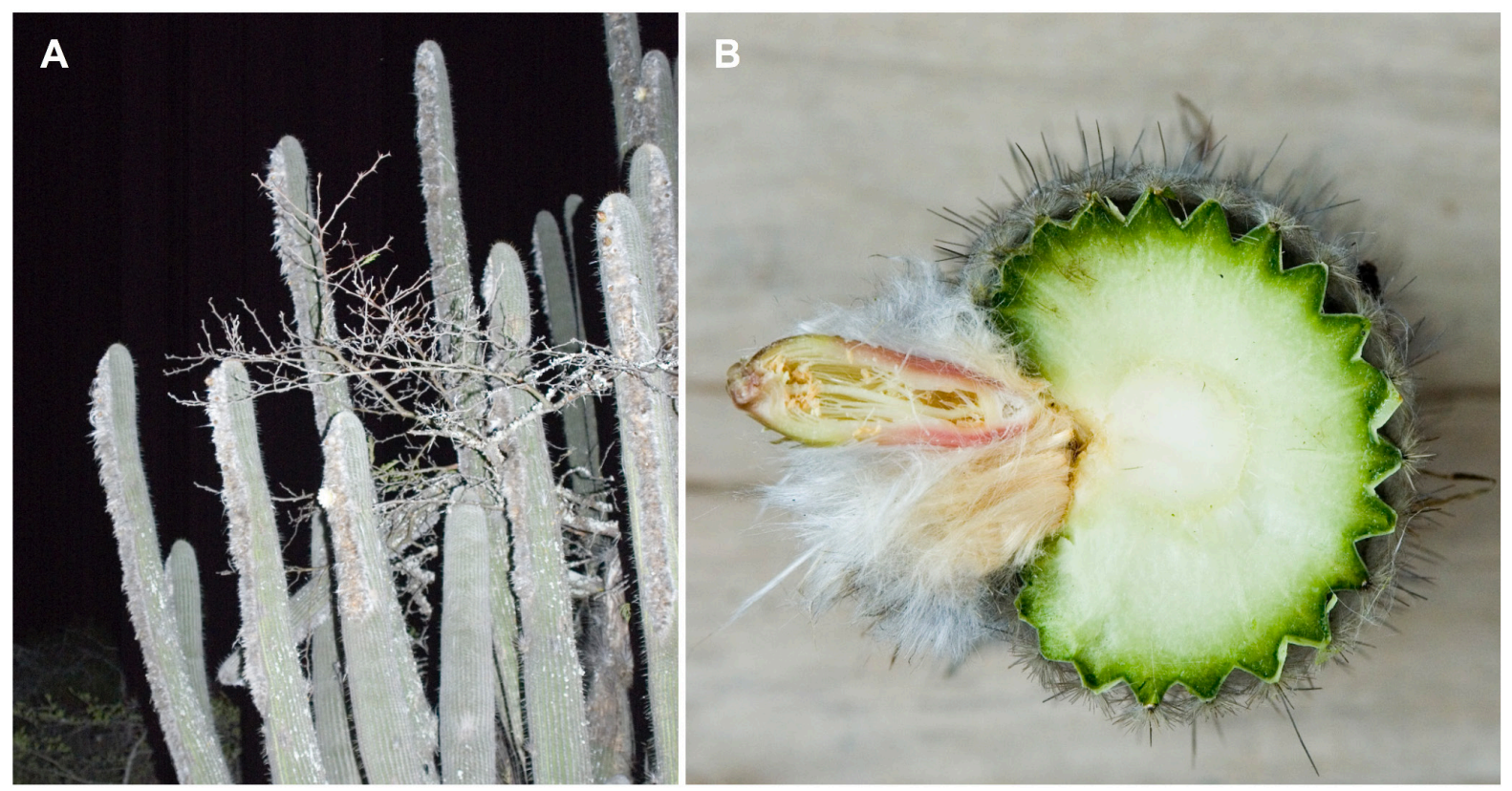

Figure S1. (A) Habitus of an Espostoa frutescens plant and (B) cross section of a column with the hairy cephalium and a closed flower. 